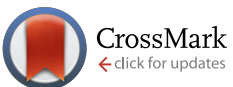

Cite this: CrystEngComm, 2015, 17, 6274

Received 3rd July 2015,

Accepted 17th July 2015

DOI: $10.1039 / \mathrm{c} 5 \mathrm{ce} 01291 \mathrm{k}$

\section{Mechanochemical and solution-based cocrystallization of 9,10-phenanthrenequinone and thiourea $\uparrow$}

\author{
Vinko Nemec, Nikola Škvorc and Dominik Cinčić*
}

\section{www.rsc.org/crystengcomm}

We have synthesized the first known cocrystal of 9,10phenanthrenequinone utilizing both liquid-assisted mechanochemical synthesis and crystallization from a solution.

In the past few years, cocrystallization has become a proven and accepted way of modifying the physical and chemical properties, such as colour, ${ }^{1}$ hygroscopicity, ${ }^{2}$ UV/Vis absorption, $^{3}$ thermal stability and solubility, ${ }^{4}$ of solid materials. Cocrystals are usually obtainable by either crystallization from a solution ${ }^{5}$ containing the desired reactant and coformer, or, more recently, by mechanochemical methods such as neat grinding (NG) or liquid-assisted grinding (LAG). ${ }^{6}$ Of the two methods, mechanochemical synthesis is preferable because it sidesteps having to find a solvent or solvent mixture that can dissolve the reactants equally, is generally much shorter with very high yield, and allows for a much better scale-up without having to significantly increase the amount of solvent used. ${ }^{7}$ Both NG and LAG have been established as fast and efficient screening methods for desired crystal forms such as cocrystals, salts, solvates and polymorphs. ${ }^{8}$

The compound we were interested in is 9,10-phenanthrenequinone (phen), a polinuclear diketone (Fig. 1) with an intense yellow colour. Up until now, phen and derivative structures have mostly been studied and used as chelating agents $^{9}$ or as pigments. ${ }^{10}$ Generally, the quinones of polycyclic aromatic hydrocarbons are abundant in all burnt organic materials, e.g. automobile exhaust and cigarette smoke. ${ }^{11}$ The title compound, phen, is a major quinone in diesel exhaust. In the context of biochemistry, many studies have focused on the mutagenicity and metabolic pathways of phen. ${ }^{12}$ It was

Department of Chemistry, Faculty of Science, University of Zagreb, Horvatovac 102a, HR-10000 Zagreb, Croatia. E-mail: dominik@chem.pmf.hr;

Fax: +385 14606341; Tel: +385 14606362

$\dagger$ Electronic supplementary information (ESI) available: Details of mechanochemical and solution syntheses, instrumental analysis, PXRD, FTIR, and DSC data. CCDC 1409744 contains crystallographic data for this paper. See DOI: $10.1039 / \mathrm{c} 5$ ce01291k reported that phen causes oxidative protein modification in living cells and accelerates malignant progression of lung cancer cells. ${ }^{12 c}$ A cursory search in the Cambridge Structural Database $^{13}$ (CSD) based on the ability of the cyclic carbonyl oxygen atom (a structural motif present in phen) to act as a hydrogen bond acceptor has resulted in 50000 hits. a)
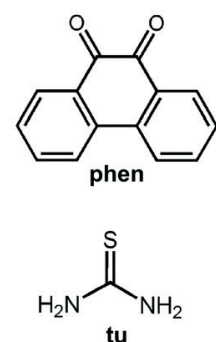

tu

c)

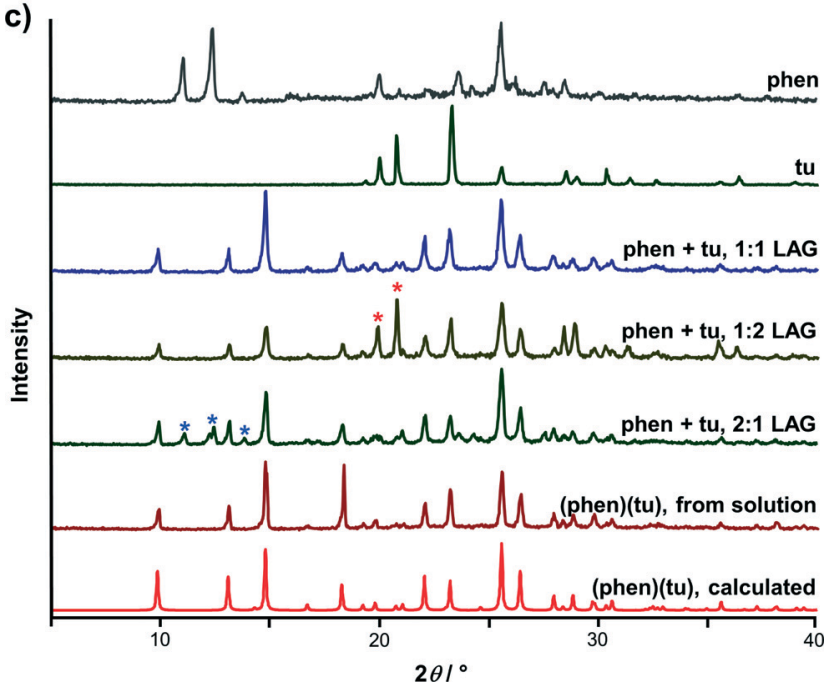

Fig. 1 (a) Structures of 9,10-phenanthrenequinone (phen) and thiourea (tu), (b) the structure obtained as a result of the single crystal X-ray diffraction experiment, (c) comparison of reactant, mechanochemical product and calculated powder patterns. Residual maxima of the reactants are marked. 
Restraining the search further to cyclic 1,2-diketones interacting with nitrogen as a hydrogen bond donor has resulted in 928 hits. Of those, 514 structures correspond to cocrystals. In spite of the fact that ketones are a valuable group of synthons in crystal engineering, no cocrystal structures have been published for phen, unlike 1,10-phenanthroline-5,6dione, a compound that is geometrically and chemically mostly analogous to phen, and a reported hydrogen and halogen bond acceptor.

Herein we report the cocrystal of phen which has been synthesized by liquid-assisted grinding. We were inspired to pursue mechanochemical experiments in our study by a recent report of Bučar and co-workers, ${ }^{1}$ who described cocrystals of fluorescein with pyridyl-based cocrystal formers. They presented a proof of principle which states that the optical properties of (poorly soluble) colourants can be altered via mechanochemical cocrystallisation, and described the efficiency of mechanochemistry in the screening for and preparation of cocrystals of such materials. In our work, as a good counterpart to phen we have selected thiourea (tu), a molecule with a significant propensity towards generating hydrogen-bonded structures. To the best of our knowledge, this is the first structurally characterised cocrystal of phen. To observe LAG mechanosynthesis, as well as to facilitate the characterisation of the new cocrystal by single-crystal X-ray diffraction, LAG experiments were accompanied by crystallization from the reactant solution. All reactants and products have been characterised by means of powder X-ray diffraction (PXRD), differential scanning calorimetry (DSC) and Fouriertransform infrared spectroscopy (FTIR). As a means to explore the stoichiometric ratio of phen and tu, we first attempted the mechanochemical synthesis of (phen)(tu) by LAG of phen and tu in stoichiometric ratios 1:1, 1:2 and 2: 1 , respectively, in the presence of a small amount of acetonitrile. Milling was conducted in a Retsch MM200 mill using a stainless steel milling assembly (see the ESI $\dagger$ ). LAG of phen and tu in a 1:1 stoichiometric ratio for 30 minutes afforded a powder material with a PXRD pattern identical to that of the crystals prepared by the solution method. In the solution experiment, equimolar amounts of phen and tu have been dissolved in a hot mixture of ethanol and benzene. The solutions were left at room temperature, and the product crystallized upon cooling. The measured PXRD patterns of (phen)(tu) obtained by both methods, grinding and from the solution, are in good agreement with those calculated from single crystal data, thus confirming that both products were obtained as a pure single phase (Fig. 1). The powder obtained by grinding and the crystals are orange, markedly different from the intensely yellow phen and white tu (Fig. 2). The other two out of the three mechanochemical experiments, LAG of phen and tu in stoichiometric ratios $1: 2$ and $2: 1$, resulted in a mixture containing (phen)(tu) cocrystals and solid reactants, as evidenced by PXRD (Fig. 1).

The (phen)(tu) cocrystal crystallizes in the orthorhombic system with four formula units per unit cell. The molecular structure of the cocrystal with the atom numbering scheme is

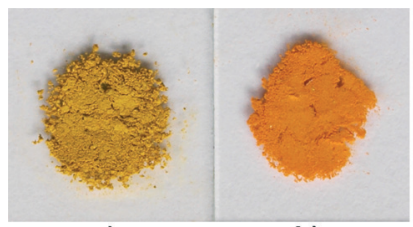

a)

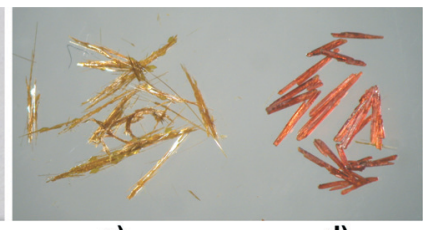

c) d)
Fig. 2 Photographs of phen and cocrystal samples: a) powder of phen; b) powder of (phen)(tu) obtained by LAG; c) crystals of phen and d) crystals of (phen)(tu).

given in Fig. S1 (see the ESI $\dagger$ ). Each phen molecule is associated with a tu molecule via a $\mathrm{N}-\mathrm{H} \cdots \mathrm{O}$ hydrogen bond $(\mathrm{N} \cdots \mathrm{O}$ distance: $3.044 \AA$, $\mathrm{N}-\mathrm{H} \cdots \mathrm{O}$ angle $154^{\circ} ; 1 / 2-x, y-1 / 2, z$ ), forming a $1: 1$ molecular complex through the $R_{2}^{2}(9)$ hydrogen bond motif ${ }^{14}$ (Fig. 3). The geometry of phen is not consistent with that normally observed for the pure phen crystal. ${ }^{15}$ The normally planar structure of phen gets twisted by about 13 degrees around the least torsionally restricted central ring. The crystal structure of (phen)(tu) can be described by association of 1:1 molecular complexes with hydrogen-bonded chains, assisted by $\mathrm{N}-\mathrm{H} \cdots \mathrm{S}$ hydrogen bonds $(\mathrm{N} \cdots \mathrm{S}$ distance: $3.403 \AA$ А $x, 1-y, z-1 / 2$ ) between tu molecules, forming a $R_{2}^{2}(8)$ motif. Also, 1:1 molecular complexes are associated with a 2-dimensional network via $\mathrm{C}-\mathrm{H} \cdots \mathrm{S}$ interactions $(\mathrm{C} \cdots \mathrm{S}$ distance: $3.898 \AA$ and $3.903 \AA$; $1-x, 1-y, 1-z$ and $x+1 / 2, y$ $-1 / 2,3 / 2-z$ ) between the aromatic carbon atoms of phen and sulfur in tu (Fig. 3). The overall structure results from the combination of such interactions and it is additionally stabilized by $\mathrm{C}-\mathrm{H} \cdots \mathrm{O}$ hydrogen bonds $(\mathrm{C} \cdots \mathrm{O}$ distance: 3.439

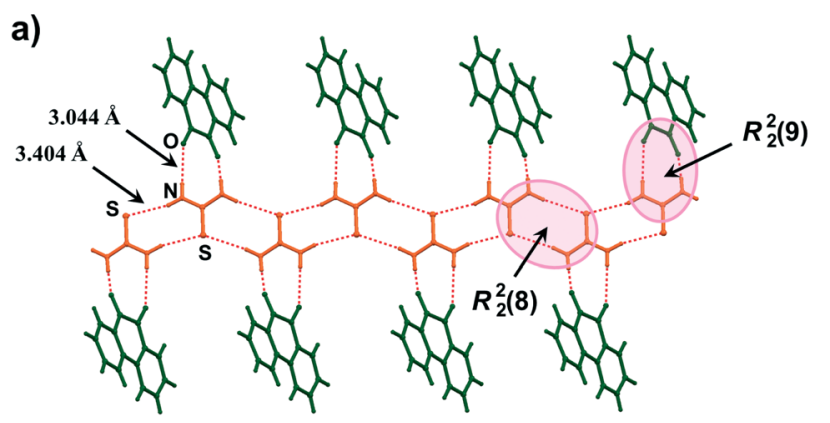

b)

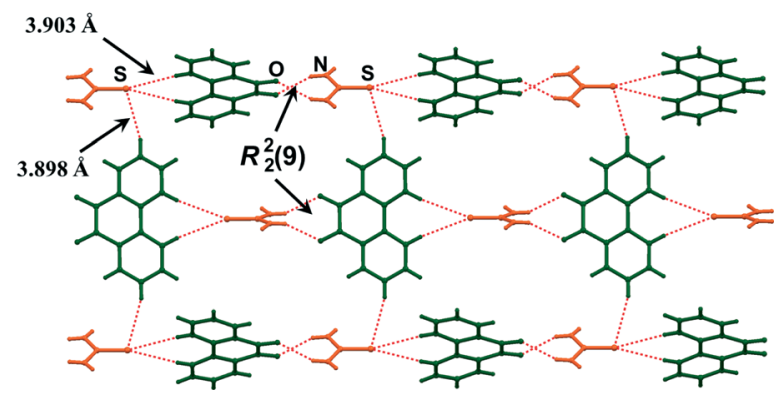

Fig. 3 The crystal structure of (phen)(tu): (a) chains of hydrogenbonded molecules via $\mathrm{N}-\mathrm{H} \cdots \mathrm{O}$ and $\mathrm{N}-\mathrm{H} \cdots \mathrm{S}$ interactions, and (b) $\mathrm{C}-$ $\mathrm{H} \cdots \mathrm{S}$ interactions and $\mathrm{N}-\mathrm{H} \cdots \mathrm{O}$ hydrogen bond motifs that give rise to the two-dimensional network. 
a)

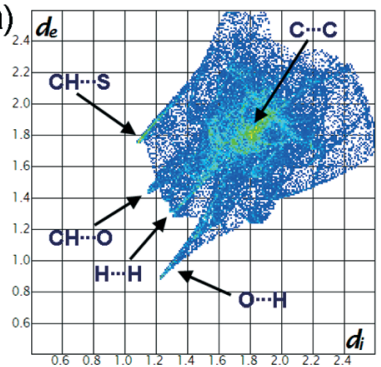

b)

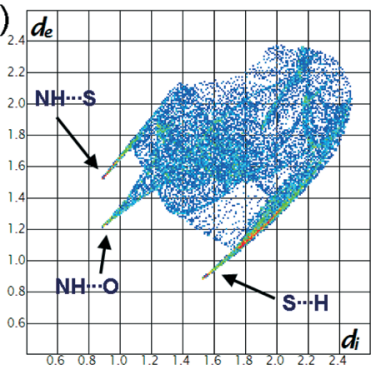

Fig. 4 Two-dimensional fingerprint plot derived from the Hirshfeld surface of the phen molecule (a) and tu molecule (b) in the (phen)(tu) cocrystal.

a)

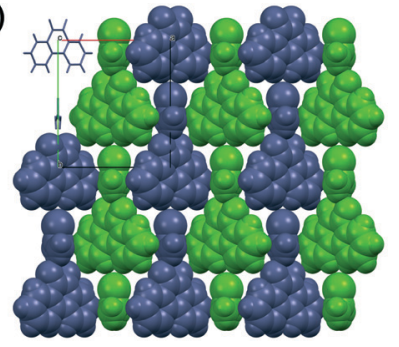

b)

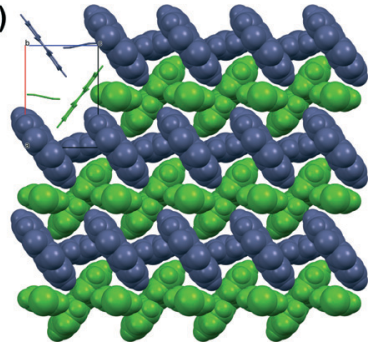

Fig. 5 Assembly of hydrogen-bonded chains of (phen)(tu) into layers viewed along the $c$ axis (a) and $b$ axis (b). For clarity, adjacent chains are colour-coded blue and green.

$\AA ; 3 / 2-x, y-1 / 2, z$ ) (Fig. 5). Also, the described interactions can be observed by a close analysis of the two-dimensional fingerprint plot derived from the Hirshfeld surface ${ }^{16}$ of the (phen)(tu) cocrystal components (Fig. 4). The cocrystal as a whole is densely packed (Fig. 5) and a notable detail of the cocrystal structure is the fact that each sulfur is a hexafurcated hydrogen bond acceptor.

To investigate the non-covalent interactions within the cocrystal, the FTIR spectra of pure phen and (phen)(tu) were recorded (see the ESI $\dagger$ ). Their spectra show strong bands corresponding to the $\mathrm{C}-\mathrm{O}$ stretching of the phen carbonyl group at about $1670 \mathrm{~cm}^{-1}\left(1676 \mathrm{~cm}^{-1}\right.$ for phen and $1650 \mathrm{~cm}^{-1}$ for the cocyrstal). The $\mathrm{C}-\mathrm{O}$ stretching for (phen)(tu) is expectedly at a lower frequency than that for pure phen due to the involvement of $\mathrm{C}-\mathrm{O}$ groups in strong intermolecular hydrogen bonds. The DSC curve of (phen)(tu) shows one endothermic peak at $175{ }^{\circ} \mathrm{C}\left(34 \mathrm{~kJ} \mathrm{~mol}^{-1}\right)$, which corresponds to the cocrystal melting point (see the ESI $\dagger$ ). It is at a lower temperature than that of pure reactants, phen $\left(206^{\circ} \mathrm{C}\right)$ and tu $\left(179^{\circ} \mathrm{C}\right)$.

In summary, we have presented the first example of a phen cocrystal obtained from the reaction of phen and tu in a 1:1 molar ratio by solid-state synthesis. Also, the (phen)(tu) cocrystal has been prepared by crystallization from a solution, despite the low solubility of phen in most organic solvents. Single-crystal X-ray analysis of (phen)(tu) revealed an interesting $R_{2}^{2}(9)$ hydrogen bond motif formed between phen and tu molecules via $\mathrm{N}-\mathrm{H} \cdots \mathrm{O}$ hydrogen bonds. Besides exploring synthetic routes, we have also found that the resulting powder material and crystals exhibit an orange

colour, markedly different from the intensely yellow phen. Crystal structure analysis demonstrates that the introduction of tu, as a cocrystal former, can change the molecular structure of phen as well as the geometric arrangement of the chromophore in the cocrystal. A number of recently reported cocrystallizations of organic solid chromophores ${ }^{1,3}$ suggest that cocrystallization provides a facile way to develop and design new types of solid organic materials with desirable optical properties, e.g. luminescence, emission, colour, and $\mathrm{UV} / \mathrm{vis}$ absorption. The described results are important in the context of supramolecular synthesis, as well as solid-state and materials chemistry, and could have significant implications for the future design and optimization of colourants, dyes and pigments via mechanochemical cocrystallization.

\section{Acknowledgements}

We acknowledge the financial support from the Ministry of Science and Technology of the Republic of Croatia (Grant No. 119-1193079-3069).

\section{Notes and references}

1 D.-K. Bučar, S. Filip, M. Arhangelskis, G. O. Lloyd and W. Jones, CrystEngComm, 2013, 15, 6289.

2 (a) T. Friščić and W. Jones, J. Pharm. Pharmacol., 2010, 62, 1547; (b) A. V. Trask, W. D. S. Motherwell and W. Jones, Int. J. Pharm. (Amsterdam, Neth.), 2006, 320, 114.

3 D. Yan, A. Delori, G. O. Lloyd, T. Friščić, G. M. Day, W. Jones, J. Lu, M. Wei, D. G. Evans and X. Duan, Angew. Chem., Int. Ed., 2011, 50, 12483.

4 (a) J. F. Remenar, S. L. Morissette, M. L. Peterson, B. Moulton, J. M. MacPhee, H. R. Guzmán and Ö. Almarsson, J. Am. Chem. Soc., 2003, 125, 8456; (b) S. L. Childs, L. J. Chyall, J. T. Dunlap, V. N. Smolenskaya, B. C. Stahly and G. P. Stahly, J. Am. Chem. Soc., 2004, 126, 13335; (c) D. P. McNamara, S. L. Childs, J. Giordano, A. Iarriccio, J. Cassidy, M. S. Shet, R. Mannion, E. O'Donell and A. Park, Pharm. Res., 2006, 23, 1888; (d) A. S. Sinha, A. R. Maguire and S. E. Lawrence, Cryst. Growth Des., 2015, 15, 984; (e) S. Aitipamula, A. B. H. Wong, P. S. Chowa and R. B. H. Tan, CrystEngComm, 2014, 16, 5793.

5 (a) P. Vishweshwar, J. A. McMahon, J. A. Bis and M. J. Zaworotko, J. Pharm. Sci., 2006, 95, 499; (b) C. B. Aakeröy, S. V. Panikkattu, B. DeHaven and J. Desper, Cryst. Growth Des., 2012, 12, 2579; (c) T. Leyssens, N. Tumanova, K. Robeyns, N. Candoni and S. Veesler, CrystEngComm, 2014, 16, 9603; (d) L. Fábián, N. Hamill, K. S. Eccles, H. A. Moynihan, A. R. Maguire, L. McCausland and S. E. Lawrence, Cryst. Growth Des., 2011, 11, 3522; (e) C. B. Aakeröy and D. J. Salmon, CrystEngComm, 2005, 7, 439; $(f)$ D. Braga, G. Palladino, M. Polito, K. Rubini, F. Grepioni, M. R. Chierotti and R. Gobetto, Chem. - Eur. J, 2008, 14, 10149.

6 (a) S. L. James, C. J. Adams, C. Bolm, D. Braga, P. Collier, T. Friščić, F. Grepioni, K. D. M. Harris, G. Hyett, W. Jones, A. 
Krebs, J. Mack, L. Maini, A. G. Orpen, I. P. Parkin, W. C. Shearouse, J. W. Steed and D. C. Waddell, Chem. Soc. Rev., 2012, 41, 413; (b) T. Friščić, Chem. Soc. Rev., 2012, 41, 3493.

7 T. Friščić and W. Jones, Cryst. Growth Des., 2009, 09, 1621.

8 (a) D. Braga and F. Grepioni, Chem. Commun., 2005, 3635; (b) A. V. Trask, D. A. Haynes, W. D. S. Motherwell and W. Jones, Chem. Commun., 2006, 51; (c) T. Friščić, I. Halasz, F. C. Strobridge, R. E. Dinnebier, R. S. Stein, L. Fábián and C. Curfs, CrystEngComm, 2011, 13, 3125; (d) T. Friščić, A. V. Trask, W. Jones and W. D. S. Motherwell, Angew. Chem., Int. Ed., 2006, 45, 7546; (e) D. Cinčić, I. Brekalo and B. Kaitner, Cryst. Growth Des., 2012, 12, 44; $(f)$ V. Stilinović, D. Cinčić, M. Zbačnik and B. Kaitner, Croat. Chem. Acta, 2012, 85, 485; (g) G. Springuel, K. Robeyns, B. Norberg, J. Wouters and T. Leyssen, Cryst. Growth Des., 2014, 14, 3996; (h) D. Cinčić, T. Friščić and W. Jones, Chem. - Eur. J., 2008, 14, 747; (i) L.-L. Han, Z.-H. Li, J.-S. Chen, X.-P. Wang and D. Sun, Cryst. Growth Des., 2014, 14, 1221; $(j)$ S. Yuan, S.-S. Liu and D. Sun, CrystEngComm, 2014, 16, 1927.

9 (a) G. Speier, Z. Tyeklar, P. Toth, E. Speier, S. Tisza, A. Rockenbauer, A. M. Whalen, N. Alkire and A. G. Pierpont, Inorg. Chem., 2001, 40, 5653; (b) R. M. Buchanan, S. L. Kessel, H. H. Downs, C. G. Pierpont and D. N. Hendrickson, J. Am. Chem. Soc., 1978, 100, 7894; (c) E. K. Brechin, L. Calucci, U. Englert, L. Margheriti, G. Pampaloni, C. Pinzino and A. Prescimone, Inorg. Chim. Acta, 2008, 361, 2375; (d) C. G. Pierpont and H. H. Downs, Inorg. Chem., 1977, 16,
2970; (e) C. G. Pierpont and R. M. Buchanan, J. Am. Chem. Soc., 1975, 97, 4912; $(f)$ S. Roy, B. Sarkar, D. Bubrin, M. Niemeyer, S. Zalis, G. K. Lahiri and W. Kaim, J. Am. Chem. Soc., 2008, 130, 15230.

10 (a) M. Burg, Light-sensitive colour forming compositions of 9, 10-phenanthrenequinone, US Pat., US3561969A, 1971; (b) B. F. Howell and K. M. Poole, UV-curable and non-volatile pigmented coatings, US Pat., US5747115A, 1998.

11 (a) Z. Tukaj and A. Aksmann, Chemosphere, 2007, 66, 480; (b) J. Ribeiro, T. Silva, J. G. M. Filho and D. Flores, J. Hazard. Mater., 2012, 199-200, 105; (c) E. Borrás, L. A. TortajadaGenaro, M. Vázquez and B. Zielinska, Atmos. Environ., 2009, 43, 5944.

12 (a) P. L. Chesis, D. E. Levin, M. T. Smith, L. Ernster and B. N. Ames, Proc. Natl. Acad. Sci. U. S. A., 1984, 81, 1696; (b) T. Matsunaga, M. Arakaki, T. Kamiya, S. Endo, O. ElKabbani and A. Hara, Chem.-Biol. Interact., 2009, 181, 52; (c) T. Matsunaga, Y. Morikawa, M. Haga, S. Endo, M. Soda, K. Yamamura, O. El-Kabbani, K. Tajima, A. Ikari and A. Hara, Toxicol. Appl. Pharmacol., 2014, 278, 180.

13 F. H. Allen, Acta Crystallogr., Sect. B: Struct. Sci., 2002, 58, 380 .

14 J. Bernstein, R. E. Davis, L. Shimoni and N.-L. Chang, Angew. Chem., Int. Ed. Engl., 1995, 34, 1555.

15 A. D. Rae and A. C. Willis, Z. Kristallogr., 2003, 218, 221.

16 J. J. McKinnon, M. A. Spackman and A. S. Mitchell, Acta Crystallogr., Sect. B: Struct. Sci., 2004, 60, 627. 